\title{
Nitrate uptake and metabolism by roots of soybean plants under oxygen deficiency.
}

\author{
Andrea D. Brandão and Ladaslav Sodek*
}

Departamento de Fisiologia Vegetal, Instituto de Biologia, Universidade Estadual de Campinas, C.P. 6109, 13083-970 Campinas - SP, Brazil

\footnotetext{
*Corresponding author; e-mail: Isodek@unicamp.br F: +55 1935216217 Fax +55 1935216210 Received: 20 January 2009; Returned for revision: 30 March 2009; Accepted: 02 April 2009
}

\begin{abstract}
Nitrate is reported to improve tolerance of plants towards oxygen deficiency imposed by waterlogging of the root system, but little is known of the mechanism underlying the phenomenon. We studied the metabolism of nitrate in roots under hypoxia, using soybean plants growing in a hydroponic system after suspending aeration and covering the surface of the nutrient solution with mineral oil. Nitrate depletion from the medium was greater under hypoxia than normoxia, but in the presence of chloramphenicol, consumption under hypoxia was significantly reduced. Nitrite accumulated in the medium under hypoxia and this was partially eliminated by chloramphenicol. Nitrate consumption sensitive to chloramphenicol was attributed to bacterial activity. Endogenous root nitrate was strongly reduced under hypoxia indicating mobilization. Although the transport of nitrate to the shoot via the xylem was also reduced under hypoxia, the severity of this reduction was dependent on the concentration of nitrate in the medium, suggesting that at least some of the nitrate in the xylem came from the medium. Root nitrate reductase was also strongly reduced under hypoxia, but recovered rapidly on return to normoxia. Overall, the data are consistent with two main metabolic fates for chloramphenicolinsensitive nitrate depletion under hypoxia: the reduction of some nitrate to nitrite (despite the reduced nitrate reductase activity) followed by its release to the medium (at least one-third of the nitrate consumed followed this route), and the transport of nitrate to the shoot. Nevertheless, it is highly unlikely that these metabolic routes account for all the nitrate consumed.
\end{abstract}

Key words: Glycine max, hypoxia, nitrate reductase, nitrite, waterlogging.

Absorção e metabolismo do nitrato em raízes de soja sob deficiência de oxigênio. É conhecido que o nitrato melhora a tolerância de plantas à deficiência de oxigênio provocada pela inundação do sistema radicular. Porém, pouco se sabe sobre as causas deste fenômeno. Realizamos um estudo do metabolismo do nitrato em raízes de soja sob hipóxia, empregando plantas cultivadas em sistema hidropônico, após suspender a aeração e cobrir a superfície da solução nutritiva com óleo mineral. 0 consumo de nitrato no meio foi maior sob hipóxia do que normóxia. Porém, na presença de cloranfenicol o consumo em hipóxia foi reduzido de forma significativa. Houve acúmulo do nitrito no meio sob hipóxia e este acúmulo foi parcialmente eliminado por cloranfenicol. A redução do consumo de nitrato na presença de cloranfenicol foi atribuída à atividade bacteriana. 0 nitrato endógeno da raiz foi bastante reduzido sob hipóxia, indicando mobilização do mesmo. Apesar do transporte do nitrato até a parte aérea, via xilema, ter sido também reduzido sob hipóxia, a intensidade dessa redução foi dependente da concentração de nitrato no meio, o que indica que pelo menos uma porção do nitrato encontrado no xilema teve origem no meio. A atividade da redutase do nitrato da raiz também foi fortemente reduzida sob hipóxia, porém recuperou-se rapidamente com o retorno à normóxia. De modo geral, os dados estão de acordo com o envolvimento de duas rotas metabólicas para explicar o consumo do nitrato que não foi inibido pelo cloranfenicol: a redução de parte do nitrato em nitrito (apesar da menor atividade de redutase do nitrato), seguida pela sua liberação no meio (pelo 
menos um terço do nitrato consumido seguiu esta rota), e 0 transporte de nitrato à parte aérea Contudo, é muito pouco provável que estas duas rotas metabólicas expliquem o consumo de todo nitrato.

Palavras-chave: Glycine max, hipóxia, redutase do nitrato, nitrito, inundação.

\section{INTRODUCTION}

Flooding is quite a common phenomenon and can occur after a short period of heavy rain, especially in poorly-drained soils. Waterlogged soils lead to a deficient supply of oxygen to the roots, in view of the diffusion rate of oxygen in water being some 10000 times slower than in air (Armstrong et al., 1994). Once the dissolved oxygen concentration falls below that necessary to maintain a normal rate of tissue respiration, by definition, the state of hypoxia is reached. The reduced rate of respiration of waterlogged roots leads to adjustments in cell metabolism that help the plant tolerate the stress. The main metabolic change involves pyruvate which switches from oxidative to fermentation metabolism, whose principal products are lactate, ethanol and alanine (Ricard et al., 1994).

Despite these metabolic changes contributing to flooding tolerance, different species show large variations in their degree of tolerance, depending not only on metabolic adaptability but also morpho-anatomic adaptations such as formation of aerenchyma and pneumatophors. Other factors also appear to be important. For example, it has been observed that the presence of nitrate in the flooding medium enhances tolerance (Malavolta, 1954; Trought and Drew, 1981; Prioul and Guyot, 1985; Bacanamwo and Purcell, 1999a,b; Kaiser and Huber, 2001; Magalhães et al., 2002) although the mechanism involved is not understood (see Sousa and Sodek, 2002a). In a previous study (Thomas and Sodek 2005), it was shown that tolerance of soybean to flooding was enhanced by $\mathrm{NO}_{3}{ }^{-}$but not by other $\mathrm{N}$ sources. Little is known of the uptake and metabolism of nitrate under $\mathrm{O}_{2}$ deficiency. Moreover, the data are conflicting. The earlier work of Lee (1978) suggests that uptake of nitrate is restricted under hypoxia of the root system and almost ceased under anoxia. Trought and Drew (1981) and Buwalda and Greenway (1989) also found reduced uptake of nitrate for wheat seedlings under anaerobic conditions. In contrast,
Morard and collaborators (2004) report that nitrate loss from the medium with excised tomato roots was strongly stimulated by anoxia. As to the metabolism of nitrate, Lee (1978) reported diminished reduction and assimilation. A hypothesis that nitrate respiration may explain the beneficial effect on flooding tolerance was proposed, since the recycling of NAD by nitrate reduction (nitrate respiration) would substitute for ethanol formation in this role (GarciaNovo and Crawford, 1973; Roberts et al., 1985). Support for the hypothesis may be found in the work of Fan and collaborators (1997) where nitrate reduced the production of ethanol in rice coleoptiles. However, in excised roots of barley (Lee, 1978) and rice (Reggiani et al., 1985b) more, not less, ethanol was produced in the presence of nitrate, thus throwing doubt upon the hypothesis. More recent evidence suggests that the beneficial effect of nitrate may involve its metabolic product nitrite (Libourel et al, 2006; Stoimenova et al, 2007).

In view of the practical implications for agriculture (Lee, 1978) of the beneficial effect of nitrate during flooding, information on nitrate uptake and its metabolism under these conditions is of fundamental importance for unravelling the mechanism involved in tolerance. In this investigation, as an initial step towards metabolic studies, our aim was to establish suitable conditions for such a study and obtain preliminary data on the uptake and metabolism of nitrate in soybean roots under hypoxia. Since $\mathrm{pH}$ and nitrate concentration in the medium can be important factors in this process, the process was studied in relation to such variables together with an assessment of the metabolic fate of nitrate after uptake by the hypoxic root system.

\section{MATERIAL AND METHODS}

Plants and growth conditions: Seeds of soybean [Glycine max (L.) Merril cv IAC-17] were germinated in trays 
of vermiculite in the greenhouse under natural conditions of light and temperature (mean min./max. of $19^{\circ} \mathrm{C}-38^{\circ} \mathrm{C}$ ). At the V0 stage (cotyledons totally open, as defined by Fehr et al. (1971)) seedlings were transplanted to a hydroponic system. Each pot contained 3 plants and a total volume of $2.5 \mathrm{~L}$ of nutrient solution ( $\mathrm{N}$ source $=\mathrm{NO}_{3}{ }^{-}$) of Hoagland and Arnon (1950) at $1 / 3$ strength, under constant aeration with compressed air (normoxia). The solution was changed every week and the pH adjusted daily to 6.5 with $\mathrm{H}_{2} \mathrm{SO}_{4}$.

Experimental set-up: The experiments with hypoxia were carried out with plants growing in a hydroponic system as described, when plants reached the V4 stage (Fehr et al., 1971) of development. The treatments used were the substitution of the nutrient solution with others at 3 different concentrations and 3 different initial pHs. The hypoxia treatment was initiated at this time by suspending the aeration of the hydroponic system together with the addition of sufficient $(70 \mathrm{~mL})$ mineral oil to cover the surface of the nutrient solution. Normally, this treatment was maintained for 4 days. In some experiments, after this period, the oil was removed with a sponge and aeration reinitiated to return the plants to normoxic conditions.

Extraction of metabolites: On harvest, the root system was washed with tap water and finally with distilled water before removing excess moisture with paper towels. The whole root system was pulverized to a fine powder under liquid nitrogen in a mortar and pestle. One $\mathrm{g}$ of the powder was extracted for $24 \mathrm{~h}$ with $10 \mathrm{~mL}$ of MCW (methanol:chloroform:water 12:5:3 v/v) according to Bielski and Turner (1966) with minor modifications. The extract was then centrifuged at $4000 \mathrm{~g}$ for 10 min. and the supernatant transferred to a measuring cylinder. The pellet was resuspended in $5 \mathrm{~mL}$ of MCW, mixed for $10 \mathrm{~min}$. and then centrifuged. The volume of the combined supernatants was measured and more chloroform (1 vol.) and water (1.5 vol) added sequentially to the supernatant (4 vol.) in a separating funnel. After shaking vigorously, the mixture was left to stand until complete separation of phases. The aqueous (upper) phase was collected and its volume reduced by a stream of $\mathrm{N}_{2}$, the volume recorded and stored at $-20^{\circ} \mathrm{C}$ until analysis.

Xylem bleeding sap: Xylem bleeding sap was collected according to McClure \& Israel (1979).

Nitrate, nitrite and total amino acid determinations: Nitrate was determined according to the method of Cataldo et al. (1975), and nitrite according to Hageman and Reed (1980). Total amino acids were determined by the ninhydrin method of Yemm and Cocking (1955), using leucine as a standard.

Nitrate reductase (NR) extraction and assay: The root system was initially washed in tap-water and finally distilled water and excess moisture removed by blotting on paper towels before maceration in a mortar and pestle with liquid nitrogen. The resulting powder was extracted ( $1 \mathrm{~g}$ in $3 \mathrm{~mL}$ ) in ice-cold $50 \mathrm{mM}$ Hepes-KOH buffer, pH 7.6, containing 5 mM EDTA, 10 $\mu \mathrm{M} \mathrm{FAD}, 3 \%(\mathrm{w} / \mathrm{v})$ casein and $1 \mathrm{mM} \mathrm{DTT}$. After centrifugation at $16.000 \mathrm{xg}$ for $10 \mathrm{~min}$ at $4^{\circ} \mathrm{C}$, the supernatant was desalted on a PD 10 (Amersham Biosciences - Sephadex G25) column equilibrated with the extraction buffer. The desalted protein fraction was assayed for nitrate reductase (E.C.1.6.6.1) activity in a mixture containing $50 \mathrm{mM}$ Hepes-KOH, pH 7.6, $5 \mathrm{mM}$ EDTA, $10 \mu \mathrm{M}$ FAD, $1 \mathrm{mM}$ DTT, $0.1 \mathrm{mM}$ NADH, $0.2 \mathrm{mM} \mathrm{KNO}_{3}$ in a total volume of $1 \mathrm{~mL}$ carried out in a $1.5 \mathrm{~mL}$ eppendorf centrifuge tube. The assays were incubated at $30^{\circ} \mathrm{C}$ for 0,15 and $30 \mathrm{~min}$ and mixed immediately with $125 \mu \mathrm{L}$ of $500 \mathrm{mM}$ $\mathrm{Zn}$ acetate to stop the reaction. The mixture was centrifuged at $16,000 \times g$ for 4 min and the supernatant assayed for the product, nitrite, according to Hageman and Reed (1980). This consisted of the sample diluted to $2 \mathrm{~mL}$ with water and mixed with $1 \mathrm{~mL}$ of $1 \%(\mathrm{w} / \mathrm{v})$ sulphanilamide in $1.5 \mathrm{~N} \mathrm{HCl}$ and $1 \mathrm{~mL}$ of $0.02 \%(\mathrm{w} / \mathrm{v}) \mathrm{N}$-(naphthyl)-ethylenediamine.2HCl. After 30 min the optical density was read in a spectrophotometer at $540 \mathrm{~nm}$ against a blank. Under the described assay conditions activity was linear with time for up to $1 \mathrm{~h}$ (confirmed in routine assays over the 30 min incubation period) and proportional to the amount of extract added.

Assay notes: Preliminary tests showed that the inclusion of $1 \%$ PVP or $10 \mu \mathrm{M}$ leupeptin during extraction did not increase extractable activity and were not used. On the other hand, increasing the concentration of casein from $0.05 \%$ (Botrel et al., 1996) to $3 \%$ was found to be beneficial. The addition of PMS $(10 \mu \mathrm{M})$ before the assay of nitrite (Botrel et al., 1996), used to oxidize surplus NADH and thereby avoid interference in the nitrite assay, was omitted since in our assay it had no effect.

Statistical Analysis: Each treatment consisted of 3 independent replicates and each replicate was the pooled material from 3 plants in a single pot. The data were subjected to an analysis of variance and differences between treatment means tested for significance by the Tukey test or Duncan's 
multiple range test (Snedecor and Cochran 1967) at the 5\% probability level.

\section{RESULTS}

Consumption of nitrate under hypoxia: The basic system used in this study consisted of soybean plants cultivated in hydroponics with a nutrient solution containing nitrate which was then subjected to hypoxia of the root system. Three concentrations of nitrate were used in the nutrient solution together with three initial pHs. Nitrate content in the medium was reduced over the $4 \mathrm{~d}$ experimental period in both the control (normoxia) and under hypoxia, but consumption was greater under hypoxia (Fig. 1). Consumption under hypoxia was in the range 8.8 to $14.5 \mathrm{mmol}$ per pot and under normoxia, 4.0 to $8.5 \mathrm{mmol}$, depending on the initial $\mathrm{pH}$ and external nitrate concentration. However, the influence of nitrate concentration and $\mathrm{pH}$ on consumption was not strong. Increasing concentrations of nitrate in the medium resulted in small but significant increases in consumption under hypoxia at pH 5.5 and 8 , but not at pH 6.5, whereas in the controls there was little effect except at $\mathrm{pH} 6.5$ where consumption decreased somewhat with increasing concentration.

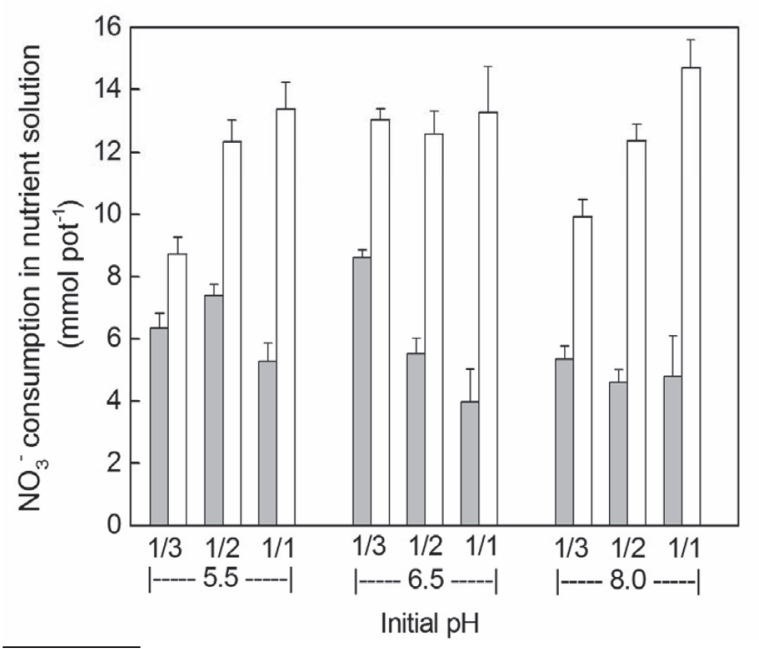

Figure 1. Nitrate consumption in the hydroponic solution $(2.5 \mathrm{~L}$ per pot) with the root system of non-nodulated soybean plants under normoxia (shaded bars) and hypoxia (open bars) over a 4-day period of treatment. Treatments: different initial concentrations of nitrate (full strength " $1 / 1$ " nutrient solution $=15 \mathrm{mM}$ nitrate, half strength " $1 / 2$ " = $7.5 \mathrm{mM}$, one-third strength " $1 / 3$ " = $5 \mathrm{mM}$ ) and initial pHs $(5.5,6.5$ and 8.0$)$. All levels of nitrate consumption under hypoxia were significantly different from the corresponding level under normoxia, except for pH5.5 1/3 $\mathrm{NO}_{3}^{-}$(Tukey test, $\mathrm{P} \leq 5 \%$ ) (not shown in figure).
The small variations in consumption at different initial pHs did not show any clear pattern. In part, the fact that the final pH (Fig. 2) at the end of the 4-day experimental period was the same or very similar for all initial pHs tested may have masked any effect of $\mathrm{pH}$ here. Thus under normoxia the final $\mathrm{pH}$ (after $4 \mathrm{~d}$ ) was around 7.5 irrespective of the initial $\mathrm{pH}$ and under hypoxia it was close to 6.5. Since in general initial $\mathrm{pH}$ and nitrate concentration (in the range studied) did not cause large variations in nitrate consumption, for routine studies $\mathrm{pH} 6.5$ was chosen together with nutrient solution at half normal strength. The fact that $\mathrm{pH}$ would remain unaltered under hypoxia at 6.5 was useful in view of the difficulty in adjusting the $\mathrm{pH}$ of the medium when the surface is covered by mineral oil.

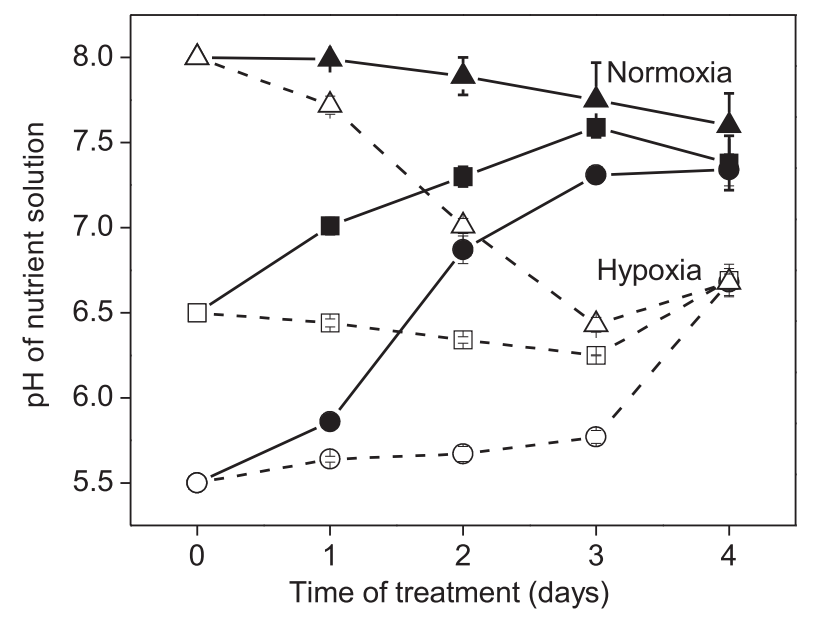

Figure 2. Variation of nutrient solution $\mathrm{pH}$ over the 4-day experimental period with the root system under normoxia (closed symbols) and hypoxia (open symbols) in a hydroponic system at different initial pHs. Nutrient solution at half strength $\left(\mathrm{NO}_{3}{ }^{-}=7.5 \mathrm{mM}\right)$ with initial pHs of $5.5,6.5$ and 8.0. Hypoxia induced by suspending aeration and covering the surface with mineral oil. Data points are the mean $( \pm S E)$ of 3 replicates.

The $\mathrm{pH}$ experiment was repeated at the initial $\mathrm{pH}$ of 6.5 (Fig. 3). Again, under normoxia the $\mathrm{pH}$ rose over the first 2 days to just above $\mathrm{pH} 7.5$ where it remained up to the end of the experiment at 8 days. Under hypoxia the initial pH of 6.5 was maintained, as before, but when the system was allowed to return to normoxia after $4 \mathrm{~d}$ under hypoxia, the $\mathrm{pH}$ rose rapidly to just above $\mathrm{pH} 7.5$, coinciding with the value shown by the controls. 


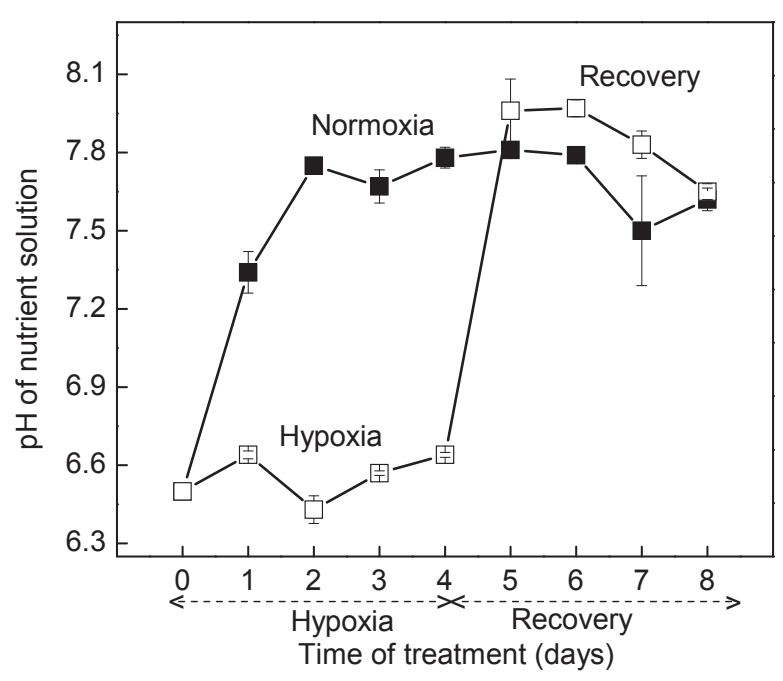

Figure 3. pH variation of the hydroponic medium under normoxia and hypoxia. After 4 days under hypoxia the system returned to normoxia for a further 4 days. Nutrient solution at $1 / 2$ strength $\left(\mathrm{NO}_{3}{ }^{-}=7.5 \mathrm{mM}\right)$ and initial $\mathrm{pH}$ at 6.5 . Data points are the mean $( \pm S E)$ of 3 replicates.

In view of the fact that the final $\mathrm{pH}$ of the control was quite different from that of the treatment with hypoxia, this, rather than hypoxia itself, could underlie the greater consumption of nitrate observed under hypoxia in the previous experiment where only the initial pH was fixed (Fig. 1). Therefore, a further experiment was conducted to measure nitrate consumption where the initial $\mathrm{pH}$ of 6.5 was maintained in the control by daily adjustments of $\mathrm{pH}$. However, from the data in Table 1 it may be seen that the consumption in the control (normoxia) was the same whether the $\mathrm{pH}$ was controlled or not (difference not statistically significant), and again the consumption was higher under hypoxia where the $\mathrm{pH}$ characteristically remains constant at pH 6.5.

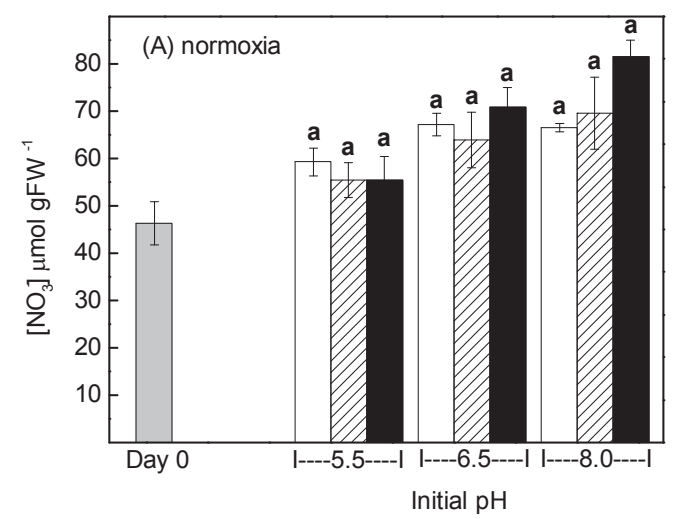

Table 1. Nitrate concentration in the hydroponic medium on cultivating nonnodulated soybean plants for 4 days under normoxia and hypoxia of the root system, with and without daily adjustment of $\mathrm{pH}^{\mathrm{a}}{ }^{\mathrm{a}}$

\begin{tabular}{|c|c|c|}
\hline Treatment & $\mathrm{pH}$ & Nitrate $\left(\mathrm{mmol} \mathrm{pot}^{-1}\right)^{\mathrm{b}}$ \\
\hline Day 0, normoxia & 6.5 & $16.07( \pm 0.38)^{a}$ \\
\hline Day 4, normoxia & 7.5 & $8.83( \pm 0.72)^{b}$ \\
\hline Day 4, normoxia & $6.5^{c}$ & $7.76( \pm 0.48)^{b}$ \\
\hline Day 4, hypoxia & 6.5 & $5.45( \pm 0.53)^{c}$ \\
\hline
\end{tabular}

${ }^{a}$ Each pot contained $2.5 \mathrm{~L}$ of nutrient solution, initially at $\mathrm{pH} 6.5 .{ }^{\mathrm{b}}$ Means $( \pm$ SE) followed by a different letter are significantly different by the Tukey test $(\mathrm{P} \leq 5 \%)$. ${ }^{\mathrm{p}} \mathrm{pH}$ adjusted daily.

Nitrate content of the roots: Using the plants from the same experiment that produced the data shown in Fig. 1, an analysis was made of the nitrate content of the roots following $4 \mathrm{~d}$ hypoxia at different initial $\mathrm{pH}$ and nitrate concentrations. The data are shown in Fig. 4. Under normoxia (Fig. 4A) it may be seen that for all treatments the endogenous root nitrate content after $4 \mathrm{~d}$ showed a small general increase relative to that found at the beginning of the experiment. However, only the increase for $15 \mathrm{mM}$ nitrate at $\mathrm{pH} 8$ was statistically significant. Although there was a tendency for higher endogenous nitrate content with higher initial pH, the differences were not significant. Nor did nitrate concentration in the medium have any significant effect on the final endogenous content, at any $\mathrm{pH}$. Overall, the data for normoxia show a tendency for nitrate to accumulate further in the roots under this condition. The data for the hypoxia treatment, however, showed a quite different situation (Fig 4B). Here, the root endogenous nitrate was strongly reduced over the 4 days of hypoxia. This effect was independent of the initial pH and nitrate concentration, since there was no significant difference between the final levels at $4 \mathrm{~d}$ for any of the treatments.

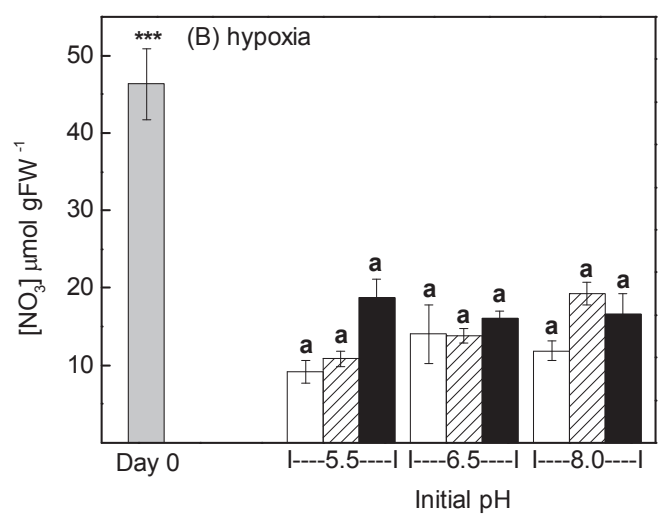

Figure 4. Nitrate content of the root system of non-nodulated soybean plants cultivated in hydroponics under (A) normoxia and (B) hypoxia for 4 days at different initial pH (5.5, 6.5 and 8.0) with different nitrate concentrations in the medium ( $5 \mathrm{mM}$ (open), $7.5 \mathrm{mM}$ (hatched) and $15 \mathrm{mM}$ (closed)). Means ( \pm SE) followed by a different letter are significantly different by Duncan's multiple range test $(P \leq 5 \%) .{ }^{* \star *}$ (hypoxia): day 0 different from any other value $(P \leq 0.1 \%)$. Normoxia: day 0 not significantly different from any other value except $15 \mathrm{mM} / \mathrm{pH} 8(\mathrm{P} \leq 5 \%)$. 
Nitrate content of the xylem bleeding sap: Data for the nitrate content of the xylem bleeding sap from the same experiment as above are shown in Fig. 5. At day 0, the sap contains nearly $20 \mu \mathrm{mol} / \mathrm{mL}$ of nitrate. Under normoxia (Fig. 5A), after 4 days at different initial pHs and nitrate concentrations, there is a fairly strong tendency for greater transport of nitrate in the xylem at higher nitrate concentrations in the medium. The nitrate concentration in the medium shows a stronger effect on xylem nitrate transport at pHs 6.5 and 8 . Relative to the day 0 value, the xylem nitrate content shows a decline at the lowest level of nitrate feeding and

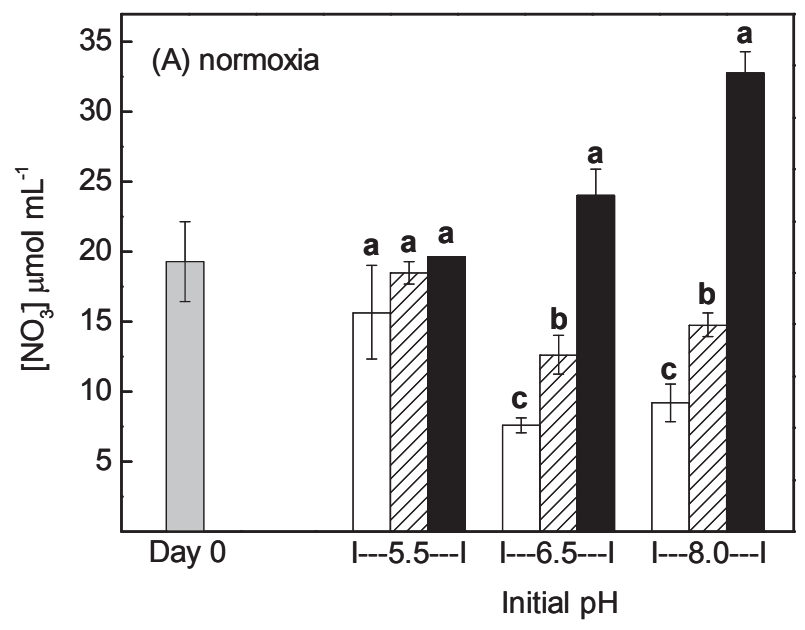

an increase at the highest level, significant at pHs 6.5 and 8. Under hypoxia (Fig $5 \mathrm{~B}$ ), there is a strong decline in nitrate content of the xylem for all treatments, but the data do show a positive effect of nitrate concentration in the medium (that is, a smaller reduction in nitrate transport at higher levels of nitrate in the medium) and an overall lack of effect of $\mathrm{pH}$, as was seen for normoxia. The level of nitrate in the xylem sap was significantly lower under hypoxia than normoxia for any concentration of nitrate in the medium and any initial pH (cf. Fig $5 \mathrm{~A}$ and $5 \mathrm{~B}$ - statistical data not shown).

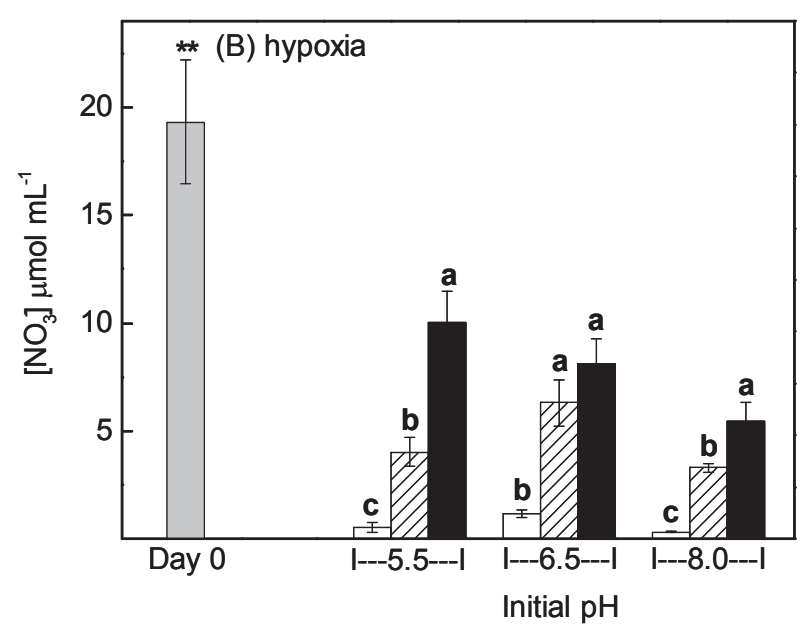

Figure 5. Nitrate content of the xylem root bleeding sap of non-nodulated soybean plants cultivated in hydroponics under (A) normoxia and (B) hypoxia for 4 days at different initial $\mathrm{pH}(5.5,6.5$ and 8.0$)$ with different nitrate concentrations in the medium (5 mM (open), $7.5 \mathrm{mM}$ (hatched) and $15 \mathrm{mM}$ (closed)). Means ( \pm SE) followed by a different letter (within $\mathrm{pH})$ are significantly different by Duncan's multiple range test $(\mathrm{P} \leq 5 \%)$. ${ }^{* *}$ (hypoxia) day 0 different from any other value $(\mathrm{P} \leq$ 1\%). Normoxia: day 0 not significantly different from any other value except $15 \mathrm{mM} / \mathrm{pH} 8,5 \mathrm{mM} / \mathrm{pH} 8$ and $5 \mathrm{mM} / \mathrm{pH} 6.5(\mathrm{P} \leq 5 \%)$.

Nitrite formation in the medium and the influence of chloramphenicol: One possible explanation for the higher consumption of nitrate in the medium under hypoxia might be its metabolism by microorganisms in the medium itself. Two approaches were used to investigate this possibility: measurement of nitrite formation (the immediate product of nitrate reduction) and measurement of nitrate consumption in the presence of the antibiotic chloramphenicol (CAP). This antibiotic was chosen in view of its specificity as an inhibitor of protein synthesis on $70 \mathrm{~S}$ ribosomes as found in bacteria, but ineffective with $80 \mathrm{~S}$ ribosomes as found in the plant cell cytoplasm. The concentration used $(50 \mu \mathrm{M})$ inhibits bacteria (Brock 1961) but much higher concentrations are required before any effect on plant systems is observed (Rabson and
Novelli 1960, Stoner et al., 1964) especially with intact plant tissue (Margulies 1962). It may be seen from the data in Table 2 that nitrite was indeed found in the medium under hypoxia and that CAP inhibited both nitrate consumption and nitrite accumulation under these conditions. Nitrite formation under hypoxia was reduced by over $50 \%$ in the presence of CAP. The inhibition of nitrate consumption was also only partial, being reduced to a level similar to that under normoxia. No nitrite was found in the medium under normoxia, nor did CAP have any significant affect on $\mathrm{pH}$ changes or nitrate consumption under these conditions. Effectively, CAP eliminated the extra consumption of nitrate found under hypoxia compared with normoxia. This was very close to the reduction in nitrite accumulation in the medium due to CAP, suggesting that 
microbial nitrate reductase activity was responsible. It might be added that the total amount of nitrite accumulated was about half of the total nitrate consumed under hypoxia in the absence of CAP and $31 \%$ when CAP was present.

Table 2. Nitrate and nitrite concentration in the medium of the hydroponic system on cultivating non-nodulated soybean plants for 4 days under normoxia and hypoxia of the root system in the presence and absence of chloramphenicol (CAP). ${ }^{\mathrm{a}}$

\begin{tabular}{|c|c|c|c|c|}
\hline & \multicolumn{2}{|c|}{ Nitrate $\left(\mathrm{mmol} \mathrm{pot}^{-1}\right)^{\mathrm{b}}$} & \multicolumn{2}{|c|}{ Nitrite $\left(\mathrm{mmol} \mathrm{pot}^{-1}\right)^{\mathrm{b}}$} \\
\hline & - CAP & $+\mathrm{CAP}$ & - CAP & + CAP \\
\hline Day 0 & $15.72( \pm 0.45) \mathrm{a}$ & - & 0.0 & - \\
\hline Day 4, normoxia & $9.99( \pm 0.21) b$ & $10.01( \pm 0.71) b$ & 0.0 & 0.0 \\
\hline Day 4, hypoxia & $6.67( \pm 0.01) c$ & $9.45( \pm 0.41) b$ & $4.74( \pm 0.98) \mathrm{a}$ & $1.94( \pm 0.31) b$ \\
\hline
\end{tabular}

${ }^{\text {a }}$ CAP used at $50 \mu \mathrm{M}$. Each pot contained $2.5 \mathrm{~L}$ of nutrient solution.

${ }^{\mathrm{b}}$ Means $( \pm \mathrm{SE})$ followed by a different letter are significantly different by the Tukey test $(P \leq 5 \%)$.

Nitrate and amino acid mobilization in the root: The levels of endogenous nitrate in the root and transport in the xylem to the shoot (Table 3) were significantly reduced after the root system had been subjected to hypoxia for $4 \mathrm{~d}$. Under normoxia, on the other hand, levels remained similar to those on day 0 . The presence of CAP in the medium had no significant effect. Amino acid levels, on the other hand, increased sharply under hypoxia both in the roots and in the xylem sap (Table 4). Under normoxia there was no change. Again, CAP had no significant influence on amino acid levels for both hypoxia and normoxia.

Table 3. Nitrate content of roots and xylem root bleeding sap on cultivating non-nodulated soybean plants in hydroponics for 4 days under normoxia and hypoxia of the root system in the presence and absence of chloramphenicol (CAP). ${ }^{\text {a }}$

\begin{tabular}{|c|c|c|c|c|}
\hline & \multicolumn{2}{|c|}{ Root tissue } & \multicolumn{2}{|c|}{ Xylem sap } \\
\hline & \multicolumn{2}{|c|}{ Nitrate $\left(\mu \mathrm{mol} \mathrm{gFW}^{-1}\right)^{\mathrm{b}}$} & \multicolumn{2}{|c|}{ Nitrate $\left(\mu \mathrm{mol} \mathrm{mL} \mathrm{L}^{-1}\right)^{\mathrm{b}}$} \\
\hline & - CAP & + CAP & - CAP & + CAP \\
\hline Day 0 & $39.2( \pm 1.2) \mathrm{a}$ & & $22.4( \pm 3.8) \mathrm{a}$ & \\
\hline Day 4, normoxia & $43.2( \pm 1.1) \mathrm{a}$ & $48.7( \pm 1.0) b$ & $27.2( \pm 0.5) \mathrm{a}$ & $24.5( \pm 2.7) \mathrm{a}$ \\
\hline Day 4, hypoxia & $17.9( \pm 0.7) c$ & $17.5( \pm 1.2) \mathrm{c}$ & $4.3( \pm 0.6) b$ & $4.8( \pm 0.7) b$ \\
\hline
\end{tabular}

${ }^{\text {a }} \mathrm{CAP}$ used at $50 \mu \mathrm{M}$.

${ }^{\mathrm{b}}$ Means $( \pm \mathrm{SE})$ followed by a different letter are significantly different by the Tukey test $(P \leq 5 \%)$.

Table 4. Amino acid content of roots and xylem root bleeding sap on cultivating non-nodulated soybean plants in hydroponics for 4 days under normoxia and hypoxia of the root system in the presence and absence of chloramphenicol (CAP). ${ }^{\text {a }}$

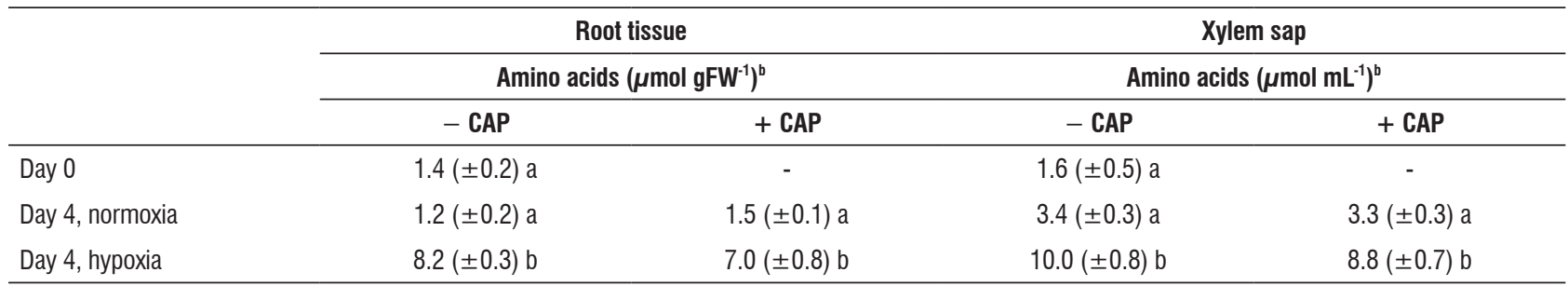

${ }^{a}$ CAP used at $50 \mu \mathrm{M}$. ${ }^{\mathrm{b}}$ Means $( \pm \mathrm{SE})$ followed by a different letter are significantly different by the Tukey test $(\mathrm{P} \leq 5 \%)$. 
Nitrate reductase: The nitrate reductase (NR) activity of the roots declined sharply during the $4 \mathrm{~d}$ period of hypoxia of the root system (Table 5). Under normoxia, the high initial values were maintained. Upon return from hypoxia, the activity rose sharply reaching the initial value within $1 \mathrm{~d}$. These data reflect the total NR activity (active plus inactive forms) since the in vitro assay was conducted in the presence of EDTA which transforms the inactive to the active form. Assays conducted in the presence of $\mathrm{Mg}^{2+}$ ions which preserves the inactive form showed that about $26 \%$ of the total activity was in the active form and this varied little throughout the experiment (data not shown).

Table 5. Nitrate reductase activity of soybean roots during a $4 \mathrm{~d}$ period of hypoxia followed by return to normoxia. ${ }^{a}$

\begin{tabular}{ccc}
\hline & \multicolumn{2}{c}{$\begin{array}{c}\text { Root nitrate reductase activity } \\
\left(\mu \mathrm{mol} \mathrm{NO}_{2} \mathrm{gfw}^{-1} \mathrm{~h}^{-1}\right)\end{array}$} \\
\hline Days & normoxia & hypoxia \\
\hline 0 & $0.91( \pm 0.16)$ & $0.91( \pm 0.16)$ \\
1 & & $0.56( \pm 0.03)$ \\
2 & & $0.35( \pm 0.02)$ \\
3 & & $0.28( \pm 0.04)$ \\
4 & $1.56( \pm 0.17)$ & $0.28( \pm 0.02)$ \\
$5^{c}$ & & $0.92( \pm 0.22)$ \\
$6^{c}$ & $1.24( \pm 0.13)$ & $0.98( \pm 0.14)$ \\
\hline
\end{tabular}

${ }^{a}$ In vitro assay in the presence of EDTA.

${ }^{\mathrm{b}}$ Means $( \pm \mathrm{SE})(\mathrm{n}=3)$

${ }^{c}$ Plants under hypoxia returned to normoxia on day 4.

\section{DISCUSSION}

Despite the beneficial role of nitrate in flooding tolerance of plants (see Introduction) little is known of the mechanism underlying this phenomenon. Conflicting data in the literature adds to the complexity of the phenomenon, much of which may be attributed to the use of a diversity of experimental systems (mainly, hypoxia $x$ anoxia, intact plants $x$ excised roots, sterile $x$ nonsterile systems). Our own data with the root system of intact soybean plants under hypoxia in nonsterile hydroponics show that nitrate consumption is higher than that for normoxia. This contrasts some data in the literature where lower rates of uptake have been found under $\mathrm{O}_{2}$ deficiency (Lee, 1978; Trought and Drew, 1981; Reggiani et al., 1985a; Buwalda and Greenway, 1989) but is in agreement with Morard and colleagues (2004) who likewise found higher nitrate uptake in excised tomato roots under anoxia. Since our experimental system involved whole plants where nitrate taken up will be metabolised and distributed throughout the plant, we measured nitrate depletion from the medium rather than uptake. However, the system is not sterile, and in doing so there is the possibility that nitrate may be metabolized by microbial activity in the medium. Nitrate can be transformed by bacteria under anaerobic conditions to nitrite, nitrous oxide and nitrogen, a process known as dissimilatory nitrate reduction (Brock, 1970). It was found that bacterial activity did indeed account for some of the nitrate depleted from the medium under hypoxia in our experimental system. The use of the antibiotic CAP in the medium reduced the consumption of nitrate under hypoxia to levels close to those found in the controls (normoxia). The accumulation of nitrite in the medium was also reduced by CAP, but not eliminated. Nevertheless, the reduction in nitrite formation due to CAP was similar to the reduction in nitrate consumption. This strongly suggests that at least some of the nitrate consumed under hypoxia can be explained by microbial activity in the medium. It is noteworthy that CAP did not alter the quantities of metabolites found in the roots or xylem, consistent with the concentration used being below that normally required to affect the plant (Stoner et al., 1964) but sufficient to suppress bacterial growth (Brock, 1961).

Nevertheless, after discounting the CAP-sensitive nitrate consumption in the medium, there is still an appreciable quantity of nitrate consumed under hypoxia that needs to be accounted for. Despite nitrate consumption under hypoxia being of the same order as for normoxia, it appears extremely unlikely that the consumption of nitrate under hypoxia follows the same metabolic pathways with similar intensities as that under normoxia, especially considering the contrasting levels of nitrate and amino acids found for normoxia and hypoxia in both the xylem sap and root tissue, plus the formation of nitrite (the CAP-insensitive fraction) found for hypoxia but not normoxia. Once nitrate has been taken up from the medium there are three main metabolic fates for this ion in root cells. First, it may be stored in the vacuole and this would represent most of the endogenous nitrate measured in the root tissue. Second, it may be reduced and assimilated forming amino acids, some of which are transported to the shoot via xylem. Third, it may be transported in the xylem for reduction and assimilation in the shoot. Nitrate content of the xylem sap would, therefore, be a reflection of the third process. Despite 
the high consumption of nitrate from the medium under hypoxia indicating as much uptake as that under normoxia, nitrate levels in the xylem sap were strongly reduced under hypoxia, as reported previously for soybean (Puiatti and Sodek, 1999; Sousa and Sodek, 2002b), and other plants under anoxia (Morard et al., 2004). The nitrate transported to the shoot under hypoxia may also originate from the declining endogenous nitrate pool and does not necessarily represent exogenous nitrate taken up from the medium. However, the amount of nitrate transported via xylem to the shoot was sensitive to the concentration of nitrate in the medium (Fig. 5) consistent with its uptake from the medium contributing to this route. From the large variations in nitrate transport obtained at different exogenous levels, it would appear that this route may well account for a significant fraction of the nitrate depleted from the medium under hypoxia. It is unlikely to account for a major fraction of the nitrate consumed however, since the similar nitrate consumption under normoxia was associated with much higher nitrate levels in the xylem sap.

Reduction and assimilation of nitrate is another important metabolic route for consideration here. In plants, green leaves are one the main sites of nitrate assimilation, which depends on the translocation of nitrate from the roots via xylem but roots can also make an important contribution, depending on the species (Smirnoff and Stewart, 1985). In soybean, the roots can account for as much as $30 \%$ of the total nitrate assimilation in the plant (Crafts-Brandner and Harper, 1982). However, under anaerobic conditions assimilation of nitrate in the roots may be seriously restricted. First, the activity of the enzyme NR, responsible for the initial step in nitrate reduction and assimilation, was found to decline sharply soon after hypoxia. This result was unexpected in view of other data in the literature where root NR activity was shown to increase under anaerobic conditions in several different species (Garcia-Novo and Crawford, 1973; Prioul and Guyot, 1985; Glaab and Kaiser, 1993; Botrel et al., 1996; Morard et al., 2004). Indeed, hypoxia has been shown to favour the active form of the enzyme in a phosphorylation/dephosphorylation mechanism of activation/ inactivation (Kaiser and Huber, 2001) but in our system not only did the total activity decrease (Table 5) but the proportion of the active:inactive forms did not change appreciably (data not shown). Second, the activity of nitrite reductase, the second enzyme of the assimilatory pathway, depends on the presence of oxygen (Lee, 1979; Botrel et al., 1996). The situation may not, however, be so clear under hypoxia where a small amount of oxygen is present (Lee, 1979) and indeed Lee (1978) found nitrate assimilation rates were less affected under hypoxia compared to anoxia. Although high rates of nitrate assimilation are found under anoxia in germinating rice (Reggiani et al., 1997), this may be a case apart in view of the high tolerance of this species to anaerobic conditions. Nevertheless, besides the lower activity of nitrate reductase, the accumulation of nitrite in our system under hypoxia is a clear indication that the further reduction and assimilation of nitrate was strongly impaired. On the other hand, since amino acids are products of nitrate assimilation, the elevated amino acid content of the roots and xylem might signal increased rather than reduced assimilation under hypoxia. However, the lower consumption of nitrate (discounting that which was not metabolized beyond nitrite) compared to that found for normoxia is not consistent with the elevated amino acid levels in the root, which were over 4 times greater under hypoxia (Table 4), arising as products of local nitrate assimilation. Evidently some other source of $\mathrm{N}$ must be responsible for much of the elevated amino acid content of roots under hypoxia. This is unlikely to be the proteolysis of root proteins since protein content of the root also increases under hypoxia (Sousa and Sodek, 2002b). An unexplored possibility is the transport of amino acids from the aerial parts via phloem to the roots.

Despite reduced nitrate reductase activity of the roots, the data do indicate appreciable nitrate reduction, but with little further reduction or assimilation, in view of the accumulation of nitrite in the medium. Nitrite accumulation in the medium, after discounting that sensitive to CAP, represented $31 \%$ of the nitrate consumed. Such activity appears, therefore, to account for a sizeable proportion of the total nitrate consumed under hypoxia. From a study of nitrate metabolism in excised tomato roots under anoxia, Morard and colleagues (2004) also found accumulation of nitrite in the medium which they attributed to nitrate reductase activity in the roots followed by efficient release to the medium. Since nitrite could account for only about half of the nitrate depleted from the medium they proposed that some nitrite might have been transformed to NO, involving a side reaction of nitrate reductase (Yamasaki and Sakihama, 2000; Rockel et al., 2002). The proposal has great interest in terms of tolerance since NO is regarded as a signal molecule involved in several stress responses, including oxygen deficiency (Magalhães et al., 2002). However, in the experiments of Morard and colleagues, in contrast to our own, nitrate reductase activity increased, 
consistent with their hypothesis, although the NR-mRNA levels did decrease after $24 \mathrm{~h}$ (Allègre et al., 2004). On the other hand, root mitochondria can also convert nitrite to NO under anaerobic conditions (Stoimenova et al., 2007) which is attractive because the process is linked to ATP generation and $\operatorname{NAD}(\mathrm{P}) \mathrm{H}$ reoxidation. The accumulation of nitrite in the medium under hypoxia found here and elsewhere (Morard et al., 2004; Libourel et al., 2006) may, therefore, favour this alternative route of nitrate metabolism.

The remaining possibility, that some of the nitrate consumed under hypoxia was stored in the vacuole of root cells, can be ruled out in view of the fact that the endogenous levels declined sharply (Fig. 4 and Table 3). A similar decline in endogenous levels was seen in a previous study where it was calculated that the mobilization of endogenous nitrate could account for much of the increase in reduced $\mathrm{N}$ compounds found in the hypoxic root, such as amino acids (Sousa and Sodek, 2002b). Under normoxia, on the other hand, the endogenous level of nitrate was maintained or even increased over the $4 \mathrm{~d}$ experimental period (Fig. 4). Mobilization of the endogenous pool of nitrate is seen when plants are transferred to a N-free medium (Puiatti and Sodek, 1999) and therefore indicative that there is no surplus nitrate for storage either because of reduced uptake or that other metabolic routes become preferential, or both. As discussed above, the evidence favours two pathways of nitrate metabolism under hypoxia: transport to the shoot via xylem and nitrate reduction in the root together with the release of the nitrite formed to the medium. The mobilized endogenous pool of nitrate may, too, follow either or both of these pathways.

Evidently our understanding of nitrate metabolism during hypoxia of the root system is just beginning to unfold. The present investigation establishes some of the conditions required for conducting such a study with the intact soybean plant, and shows that nitrate metabolism suffers a radical change under hypoxia. The data suggest that as much nitrate may be taken up from the medium under hypoxia as normoxia (discounting nitrate depletion sensitive to the antibiotic CAP). Of the more commonly found pathways of nitrate utilization, it appears that under hypoxia: nitrate is not accumulated in the root; a significant but reduced fraction is transported via xylem to the shoot; and, although reduction and especially assimilation are apparently diminished, reduction (leading to nitrite accumulation in the medium) represents a sizeable proportion of the nitrate metabolized. Nevertheless, these pathways cannot account for all the nitrate consumed under hypoxia, which leaves room for other proposals such as the transformation of nitrite to NO (Morard et al., 2004; Stoimenova et al (2007).

\section{CONCLUSIONS}

Large differences in the metabolism of nitrate were found for the root system of soybean maintained in a hydroponic medium under hypoxia compared with normoxia, despite the consumption of nitrate over the 4-day experimental period being of the same order. Consumption of nitrate under hypoxia was even greater if bacterial activity in the medium was not controlled with antibiotic. Nitrate assimilation in the roots and the transport of nitrate to the shoot via xylem under hypoxia were only a small fraction of that under normoxia. No nitrate accumulated in the roots under hypoxia; rather, endogenous nitrate was mobilized. A significant portion of nitrate was reduced to nitrite which accumulated in the medium. Other pathways of nitrate metabolism must be sought to explain much of the nitrate consumed under hypoxia.

Acknowledgements: The authors wish to thank FAPESP for financial support and CNPq for the award of a scholarship to ADB.

\section{REFERENCES}

Allègre A, Silvestre J, Morard P, Kallerhoff J, Pinelli, E (2004) Nitrate reductase regulation in tomato roots by exogenous nitrate: a possible role in tolerance to long-term root anoxia. J. Exp. Bot. 55: 2625-2634.

Armstrong W, Brändle R, Jackson MB (1994) Mechanisms of flood tolerance in plants. Acta Bot. Neerl. 43: 307-358.

Bacanamwo M, Purcell LC (1999a) Soybean root morphological and anatomical traits associated with acclimation to flooding. Crop Sci. 39: 143-149.

Bacanamwo M, Purcell LC (1999b) Soybean dry matter and N accumulation responses to flooding stress, $N$ sources and hypoxia. J. Exp. Bot. 50: 689696.

Bielski LR, Turner NA (1966) Separation and estimation of amino acids in crude plant extracts by thin-layer electrophoresis and chromatography. Analyt. Biochem. 17: 278-293.

Botrel A, Magné C, Kaiser WM (1996) Nitrate reduction, nitrite reduction and ammonium assimilation in barley roots in response to anoxia. Plant Physiol. Biochem. 34: 645-652.

Brock TD (1961) Chloramphenicol. Bacteriol. Ver. 25: 32-48.

Brock TD (1970) Biology of Micro-organisms. Prentice-Hall, New Jersey. $116 p$. 
Buwalda F, Greenway H (1989) Nitrogen uptake and growth of wheat during $\mathrm{O}_{2}$ deficiency in root media containing $\mathrm{NO}_{3}^{-}$only, or $\mathrm{NO}_{3}^{-}$plus $\mathrm{NH}_{4}^{+}$. New Phytol. 111: 161-166.

Cataldo DA, Haroon M, Schrader LE, Youngs VL (1975) Rapid colorimetric determination of nitrate in plant tissue by nitration of salicylic acid. Commun. Soil Sci. Anal. 6: 71-80.

Crafts-Brandner SJ, Harper JE (1982) Nitrate reduction by roots of soybean (Glycine max [L.] Merr.) seedlings. Plant Physiol. 69: 1298-1303.

Fan TWM, Higashi RM, Frenkiel TA, Lane AN (1997). Anaerobic nitrate and ammonium in flood-tolerant rice coleoptiles. J. Exp. Bot. 48: 1655-1666.

Fehr WR, Caviness DT, Burmood JS, Pennington JS (1971) Stage of development descriptions for soybean. Crop Science 11: 929-931.

Garcia-Novo F, Crawford RMM (1973) Soil aeration, nitrate reduction and flooding tolerance in higher plants. New Phytol. 72: 1031-1039.

Glaab J, Kaiser WM (1993) Rapid modulation of nitrate reductase in pea roots. Planta 191: 173-179.

Hageman RH, Reed AJ (1980) Nitrate reductase from higher plants. Methods Enzymol. 69: 270-280.

Hoagland DR, Arnon DI (1950) The water culture method for growing plants without soil. Calif. Agric. Exp. Sta., Bulletin 347.

Kaiser MW, Huber SC (2001) Post-translational regulation of nitrate reductase: mechanism, physiological relevance and environmental triggers. J. Exp. Bot. 52: $1981-1989$

Lee RB (1978) Inorganic nitrogen metabolism in barley roots under poorly aerated conditions. J. Exp. Bot. 29: 692-708.

Lee RB (1979) The release of nitrite from barley roots in response to metabolic inhibitors, uncoupling agents and anoxia. J. Exp. Bot. 30: 119-133.

Libourel IGL, van Bodegom PM, Fricker MD, Ratcliffe RG (2006) Nitrite reduces cytoplasmic acidosis under anoxia. Plant Physiol. 142: 1710-1717.

McClure PR, Israel DW (1979) Transport of nitrogen in the xylem of soybean plants. Plant Physiol. 64: 411-416.

Magalhães JR, Silva FLIM, Salgado I, Ferrarese-Filho 0, Rockel P, Kaiser WM (2002) Nitric oxide and nitrate reductase in higher plants. Physiol. Mol. Biol. Plants 8: 11-17.

Malavolta E (1954) Studies on the nitrogenous nutrition of rice. Plant Physiol. 29: 98-99.

Margulies MM (1962) Effect of chloramphenicol on light dependent development of seedlings of Phaseolus vulgaris var. Black Valentine with particular reference to development of photosynthetic activity. Plant Physiol. 37: 473-480.

Morard P, Silvestre J, Lacoste L, Caumes E, Lamaze T (2004) Nitrate uptake and nitrite release by tomato roots in response to anoxia. J. Plant Physiol. 161: 855-865.

Prioul JL, Guyot C (1985) Role of oxygen transport and nitrate metabolism in the adaptation of wheat plants to root anaerobiosis. Physiol. Veg. 23: 175185.
Puiatti M, Sodek L (1999) Waterlogging affects nitrogen transport in the xylem of soybean. Plant Physiol. Biochem. 37: 767-773.

Rabson R, Novelli GD (1960) The incorporation of leucine- $\mathrm{C}^{14}$ into protein by a cell-free preparation from maize kernels. PNAS 46: 484-488.

Reggiani R, Brambilla I, Bertani A (1985a) Effect of exogenous nitrate on anaerobic metabolism in excised rice roots. I. Nitrate reduction and pyridine nucleotide pools. J. Exp. Bot. 36: 1193-1199.

Reggiani R, Brambilla I, Bertani A (1985b) Effect of exogenous nitrate on anaerobic metabolism in excised rice roots. II. Fermentation activity and adenylic energy charge. J. Exp. Bot. 36: 1698-1704.

Reggiani R, Bertani F, Mattana M (1997) Incorporation of nitrate nitrogen in rice seedlings transferred to anaerobic conditions. Amino Acids 13: 183188.

Ricard B, Couée I, Raymond P, Saglio PH, Saint-Ges V, Pradet A (1994) Plant metabolism under hypoxia and anoxia. Plant Physiol. Biochem. 32: 1-10.

Roberts JKM, Andrade F, Anderson IC (1985) Further evidence that cytoplasmic acidosis is a determinant of flooding intolerance in plants. Plant Physiol. 77: 492-494.

Rockel P, Strube F, Rockel A, Wildt J, Kaiser WM (2002) Regulation of nitric oxide (NO) production by plant nitrate reductase in vivo and in vitro. J. Exp. Bot. 53: 103-110.

Stoner CD, Hanson JB, Hodges TK (1964) Chloramphenicol as inhibitor of energy-linked processes in maize mitochondria. Nature, London 203: 258261.

Smirnoff N, Stewart GR (1985) Nitrate assimilation and translocation by higher plants: comparative physiology and ecological consequences. Physiol. Plant. 64: 133-140.

Snedecor GW, Cochran WG (1967) Statistical Methods. $6^{\text {th }}$ Ed., lowa State Universtity Press, Ames, lowa.

Sousa CAF, Sodek $L$ (2002a) The metabolic response of plants to oxygen deficiency. Braz. J. Plant Physiol. 14: 83-94.

Sousa CAF, Sodek L (2002b) Metabolic changes in soybean plants in response to waterlogging in the presence of nitrate. Physiol. Mol. Biol. Plants 8: 97-104.

Stoimenova M, Igamberdiev AU, Gupta KJ, Hill RD (2007) Nitrite-driven anaerobic ATP synthesis in barley and rice root mitochondria. Planta 226: 465-474.

Thomas AL, Sodek $L$ (2005) Development of the nodulated soybean plant after flooding of the root system with different sources of nitrogen. Braz. J. Plant Physiol. 17: 291-297.

Trought MCT, Drew MC (1981) Alleviation of injury to young wheat plants in anaerobic solution cultures in relation to the supply of nitrate and other inorganic nutrients. J. Exp. Bot. 32: 509-522.

Yamasaki H, Sakihama Y (2000) Simultaneous production of nitric oxide and peroxynitrite by plant nitrate reductase: in vitro evidence for NR-dependent formation of active nitrogen species. FEBS Lett. 468: 89-92.

Yemm EW, Cocking EC (1955) The determination of amino acids with ninhydrin. Analyst 80: 209-213. 